Human and Animal Health

Vol.59: e16150033, January-December 2016 http://dx.doi.org/10.1590/1678-4324-2016150033 ISSN 1678-4324 Online Edition

\title{
Heregulin-1及 Promotes the Synergistic Effect Between Allogenic Skin-Derived Precursor Differentiated Schwann Cells (SKP-SC) and Acellular Nerve Allograft (ANA) in Peripheral Nerve Regeneration Through Inhibiting Mir-21
}

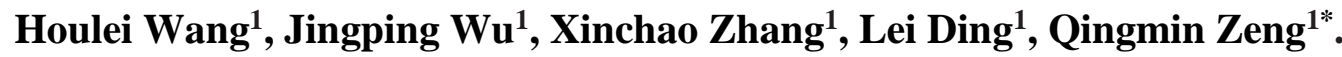 \\ ${ }^{1}$ Department of Orthopedics, Jinshan Hospital of Fudan University, Shanghai, China.
}

\begin{abstract}
Previous studies in our lab found that heregulin-1 $\beta$ with SKP-SCs (neurons and Schwann cells differentiated from SKPs) / ANA (acellular nerve allograft) transplantation represented a powerful therapeutic approach, and facilitates the efficacy of ANA in peripheral nerve injury. In this study, our purpose is to explore the mechanism between them. Firstly we transplanted ANA + SKP-SC + heregulin-1 $\beta$ into rats with right sciatic nerve injury and then detected the miR-21 and SOX2 (SRY-like HMG box 2) levels. Then we transfected miR-21 inhibitor in SCs (Schwann cells) which induced in hypoxic condition before harvesting. Then we detected expression of miR-21 and SOX2 using real time$P C R$ and western blot assay. Results in vivo showed that the expression of miR-21 in rats was inhibited after transplantation of ANA + SKP-SC + heregulin-1 $\beta$ with induced SOX2 accordingly. Then we found miR-21 was increased time dependently in hypoxic SCs with decreased SOX2 accordingly. After miR-21 inhibitor transfection, miR-21 level was reduced and SOX2 was up-regulated. Meanwhile it was also showed that the miR-21 inhibitor induced the hypoxic SCs growth, decreased the apoptosis with cell cycle changing. In conclusion miR-21 and its target gene SOX2 played important role in peripheral nerve injury. Heregulin-1 $\beta$ may increase the synergistic effect between SKP-SC and ANA through inhibiting miR-21 in vivo.
\end{abstract}

Key Words: Peripheral nerve injury, ANA, SKP-SC, heregulin-1 $\beta$, miR-21, SOX2

*Authors for correspondence: qingminzeng1703@163.com 


\section{INTRODUCTION}

Peripheral nerve injury, which carries a high cost to healthcare systems and affect 13 to 23 per $1 \times 10^{5}$ persons each year, is categorized in the Seddon classification based on the extent of damage to both the nerve and the surrounding connective tissuein level one trauma centers(Chhabra et al., 2014; Kaya and Sarikcioglu, 2015).Especially in response to proximal sectioning of axons, some nerve cells might go to apoptosis, with permanently lower number of regenerating neurons. Unlike in the central nervous system, regeneration and reinnervation in the peripheral nervous system is capable even it is fragile and easily damaged, which can be due to neuropathies, traumatic injury, tumor-related surgery or repetitive compression (Evans, 2001; Griffin et al., 2014; Pfister et al., 2011).

Schwann cells (SCs) are the endogenous and principal glial cells of the peripheral nervous system and orchestrators of regeneration, which can switch from a myelinating to a phagocytic phenotype, through chemotactic signaling, and then recruit circulating macrophages into the zone of injury (Gomez-Sanchez et al., 2015; Kegler et al., 2015). Any interruption during the process of reuniting SCs and the regenerating axon might result in chronic SC senescence, down-regulation, a loss of axonal support and compromised recovery (Li et al., 2001). Acellular nerve allograft (ANA) is one of the most promising substitutes for nerve autografts. Peripheral nerve allograft is available in great abundance and offers the potential for size/length and motor/sensory specificity (Zhang et al., 2015). Processing nerve allograft is limited to short gap distances of $3 \mathrm{~cm}$ without enough viable SCs whose number and activity have been emphasized in the peripheral nervous system (Saheb-Al-Zamani et al., 2013). It is necessary to achieving sufficient autologous SC numbers with explanation of healthy nerve. Any interruption and damage of healthy peripheral nervous system result in irreversible loss of SCs. Besides, primary Schwann cells are not accessible for harvest and seeding into autografts, as a result, the use of cultured stem cells which can differentiate into SCs in vitro considered impractical (Kitada, 2012). The differentiation of stem cells into Schwann cells and neural stem cells were proposed as candidates for transplantation with the potential to replace lost neurons or increase the number of glial support cells, and finally rescue and replenish axotomized neurons (Kitada, 2012; Vroemen et al., 2007).

Recently, skin-derived precursors (SKPs), a type of novel multipotent progenitor cell, have been reported in the dermis of both neonatal and adult skin, which are characterized by similar gene expression patterns and functional properties as neural crest-derived cells in the embryonic stage (McKenzie et al., 2006; Sparling et al., 2015). Previous research demonstrated that SKPs can be induced to differentiate into neurons and Schwann cells (SKPSCs) under specific differentiating culture conditions (Fernandes et al., 2004; Zhang et al., 2014), which may be an accessible and efficacious cell source for remarkably promoting peripheral nerve regeneration in $15 \mathrm{~mm}$ nerve defects in rats through being seeded into ANA (Seo et al., 2013).

MicroRNAs (miRNAs) are a class of non-coding small RNAs, 18-22 nucleotides in length, which bind to target genes and then suppress the translation or induce degradation of the target gene mRNA(Liu et al., 2016).As a well-characterized oncogenic miRNA, miR-21 is consistently up-regulated in the dorsal root ganglion (DRG) after peripheral nerve injury, where the primary sensory neurons exist (Sakai and Suzuki, 2013). It is implied that miR-21 and its modulatory system may be a therapeutic target for intractable chronic neuropathic pain. Many previous studies demonstrated the direct interaction between miR-21 and SOX2. The induction of miR21 strongly inhibited SOX2 expression andthe opposite effect was observed upon miR-21 inhibition strikingly (Polajeva et al., 2012; Singh et al., 2015; Trohatou et al., 2014; Yang and Rana, 2013).

Previous studies in our lab found that heregulin- $1 \beta$ with SKP-SCs/ANA transplantation represented a powerful therapeutic approach, and facilitates the efficacy of acellular nerve allograft in peripheral nerve injury. However the detailed mechanism remains to be elucidated, which we explored in this study. First we found and validated miR-21 and its target gene SOX2 played important role in peripheral nerve injury in vitro. And then it was suggested that heregulin-1 $\beta$ may increase the synergistic effect between SKP-SC and ANA through inhibiting miR21 in vivo.

\section{MATERIAL AND METHOD \\ Generation and culture of Skin-derived precursor cells- Schwann cells (SKP-SCs)}


Skin-derived precursor cells (SKPs) were generated from dermis of postnatal day 2 Wistar ratsand cultured according to published protocols (Walsh et al., 2010). Briefly, pups were quickly decapitated and skin on the dorsal torso was sterilized with a $70 \%$ EtOH swab prior to removal with sterile scissors. Collected tissue was minced in Hank's Balanced Salt Solution (HBSS) on ice and then incubated for approximately $45 \mathrm{~min}$ in $0.1 \%$ collagenase at $37^{\circ} \mathrm{C}$. Skin pieces were mechanically dissociated, washed in cold DMEM and passed through a $40 \mu \mathrm{m}$ cell strainer. Filtrate was centrifuged at $1200 \mathrm{rpm}$ and the pellet was triturated and resuspended to a concentration of 50,000 cells $/ \mathrm{mL}$ in culture media (DMEM-F12， 3:1， Gibco), containing 1\% penicillin/streptomycin (Sigma), B-27, $20 \mathrm{ng} / \mathrm{mL}$ EGF, and $40 \mathrm{ng} / \mathrm{mL}$ bFGF (Gibco). Cells were cultured and passaged three times as undifferentiated spheres in $25 \mathrm{~cm}^{2}$ tissue-culture flasks (Corning) in a $37{ }^{\circ} \mathrm{C}, 5 \% \mathrm{CO}_{2}$ tissue-culture incubator. The SKPs were confirmed with the staining of nestin and fibronectin on cell surface.

To induce differentiation towards Schwann cells, spheres were triturated and replaced on poly-dlysine/laminin coated culture dishes (Corning) in DMEM/F12 media with $4 \mu \mathrm{M}$ forksolin, $10 \mathrm{ng} / \mathrm{mL}$ heregulin-1 $\beta$, and $1 \% \mathrm{~N} 2$ supplement (Gibco). After incubation for 1 week, cells appearing under phase contrast to have bipolar SC morphology were isolated with cloning cylinders and expanded in the same medium until > $95 \%$ purity was achieved(Jessen and Mirsky, 1992). SCs were assessed with p75NGFR and S100- $\beta$ staining (Method of SKP-SCs generation and culture was the same with another paper in our lab which is under review now).

\section{Procedure of acellular nerve allograft (ANA)}

Twenty adult SD rats (200-250 g) underwent sciatic nerve transection and repaired with ANAs. Donor rats were anesthetized with chloral hydrate (350 $\mathrm{mg} / \mathrm{kg}$ ) during all surgical procedures. All surgeries were performed bilaterally. After skin incision, the sciatic nerve and its branches were exposed bilaterally following a gluteal splitting incision. With the aid of an operation microscope, the sciatic nerve $(20 \mathrm{~mm})$ was severed and removed closed to the obturator tendon in the mid-thigh. To prepare the ANA, the 20-mm sciatic nerve was rinsed with HBSS and freezed in liquid nitrogen for 2 min following a 2 min rewarming 2 times, and stored in liquid nitrogen. Prior to transplantation one day, the ANA was incubated with $2 \mathrm{U} / \mathrm{mL}$ chondroitinase $\mathrm{ABC}$ or PBS for $16 \mathrm{~h}$ at $37^{\circ} \mathrm{C}$, then washed 2 times with HBSS and stored in $0{ }^{\circ} \mathrm{C}$ (ANA procedure was the same with another paper in our lab which is under review now).

\section{Animal experiment}

Male Sprague Dawley (SD) rats (7-8weeks old, 250$300 \mathrm{~g}$ ) were obtained from Shanghai Laboratory Animal Center. All animal experiments were approved by the Institutional Animal Care and Use Committee of Fudan University, China. The temperature was $22 \pm 1{ }^{\circ} \mathrm{C}$. The humidity was $55 \pm$ $5 \%$. The photoperiod is 12 hours a cycle. There were 4 rats in every cage.

After a 3 days' adapting period, 16 SD rats were divided into 2 groups $(n=8$ rats each): ANA + SKPSC $(n=8)$, and ANA + SKP-SC + heregulin-1 $\beta$ treated group $(n=8)$, and underwent exposure of the right sciatic nerve injury. With the aid of an operation microscope, the recipient nerve was transected at 5 $\mathrm{mm}$ proximal to the sciatic trifurcation and $15-\mathrm{mm}$ nerve was removed. The defect was reconstructed with an ANA. The graft was coated to the host nerve stumps by epineurial neurorrhaphy using one 9-0 proline suture at each end. For ANA+SKP-SC and ANA + SKP-SC + heregulin- $1 \beta$ treated groups, $3 \mu \mathrm{L}$ of $2 \times 10^{6}$ cells $/ \mathrm{mL}$ SKP-SCs were injected into an ANA at the proximal end and distal end from the anastomosis $3 \mathrm{~mm}$ using a micro-injector under an SXP-10 microscope at 10x magnification, respectively. For ANA + SKP-SC + heregulin-1 $\beta$ treated group, $500 \mathrm{ng} / \mathrm{mL}$ of heregulin- $1 \beta$ was injected into the ANA.

At the 8-week endpoints, the sciatic nerve was harvested en bloc $\sim 3 \mathrm{~mm}$ proximal and $\sim 4 \mathrm{~mm}$ distal to the interposed graft. The nerves were stored in $3 \%$ glutaraldehyde or $4 \%$ paraformaldehyde until use.

\section{Culture and treatment of Schwann cells}

Schwann cells (SCs) were isolated from sciatic nerves of 1-day-old SD rats and treated to remove the fibroblasts using anti-Thy1.1 antibody (Sigma, St Louis, MO) and rabbit complement (Invitrogen, Carlsbad, CA) as previously described. The final cell preparation consisted of $98 \% \mathrm{SCs}$, as determined by immunostaining with S100 $\beta$, a specific SC marker (data not shown). Primary cultureof SCs was maintained in Dulbecco's modified Eagle's medium (DMEM) containing $10 \%$ fetal bovine serum (complete medium) at $37{ }^{\circ} \mathrm{C}$ under humidified $5 \%$ $\mathrm{CO}_{2}$. The cell culture was passaged no more than three times before the following tests. To induce the 
hypoxic condition in vitro, SCs were cultured at 37 ${ }^{\circ} \mathrm{C}$ in a humidified incubator with a mixture of $1 \%$ $\mathrm{O}_{2} / 5 \% \mathrm{CO}_{2} / 94 \% \mathrm{~N}_{2}$ for indicated times. Primary cultured SCs were transfected with miR-21 inhibitor mimic, or miR-NC (negative control, Ribobio, Guangzhou, China), respectively, using Lipofectamine RNAiMAX transfection reagent (Invitrogen).

Total RNA isolation, reverse-transcription and RT-PCR for mRNA

Total RNA was isolated by using a UNIQ-10 column and TRIZOL Total RNA Isolation Kit (Sangon, Shanghai, China). One microgram of total RNA was used for reverse transcription in a reaction volume of $20 \mu \mathrm{L}$ using Cloned AMV Reverse Transcriptase (Invitrogen, Carlsbad, CA).

Table 1- Sequence of the gene-specific primers used for real-time PCR detection in vitro and in vivo.

\begin{tabular}{cc}
\hline gene & Primer sequence $\left(5^{\prime}\right.$-3’' $^{\prime}$ \\
SOX2 & Forward: GGGCTCTGTGGTCAAGTC \\
& Reverse: TAGTCGGCATCACGGTTT \\
GAPDH & Forward: CGGAGTCAACGGATTTGGTCGTAT \\
& Reverse: AGCCTTCTCCATGGTGGTGAAGAC \\
miR-21 & Forward: GCCGCGTAGCTTATCAGACT \\
& Reverse: CTCAACTGGTGTCGTGGA \\
U6 & Forward: CTCGCTTCGGCAGCACA \\
& Reverse: AACGCTTCACGAATTTGCGT \\
\hline
\end{tabular}

\section{Quantitative RT-PCR of mature miRNAs}

Real-time quantification was performed using an Applied Bio systems 7500 Sequence Detection system. The $20 \mu \mathrm{L}$ PCR reaction included $1 \mu \mathrm{L}$ RT product (1:5 dilution), $0.5 \mu \mathrm{L}$ Universal reverse primer, $0.5 \mu \mathrm{L}$ of sense primer, and $10 \mu \mathrm{L}$ mix buffer (DBI Bestar® SybrGreen qPCR masterMix). The reactions were incubated in a tube (DBI Bestar ${ }^{\circledR}$ SybrGreen qPCR masterMix). The reactions were incubated in a 96 -well optical plate at $94{ }^{\circ} \mathrm{C}$ for 2 min, followed by 40 cycles of $94{ }^{\circ} \mathrm{C}$ for $20 \mathrm{~s}, 58{ }^{\circ} \mathrm{C}$ for $20 \mathrm{~s}$ and $72{ }^{\circ} \mathrm{C}$ for $20 \mathrm{~s}$. All reactions were run in triplicate. miR-21 and U6 primers used are listed as Table 1.
Two microliters of cDNA were used for real time PCR using TaKaRa Ex Taq RT-PCR Version 2.1 kit (TaKaRa, Shiga, Japan). Gene-specific PCR primers for SOX2 and GAPDH are listed as Table 1, and PCR signals were detected with a DA Engine Opticon 2 Continuous Fluorescence Detection System (Bio-Rad, Hercules, CA, USA). PCR was monitored for 45 cycles sing an annealing temperature of $60^{\circ} \mathrm{C}$. At the end of the PCR cycles, melt curve analysis and $2 \%$ agar electrophoresis was performed to assess the purity of the PCR products. Negative control reactions (no template) were routinely included to monitor potential contamination of reagents. Relative amounts of SOX2 mRNA were normalized to that of GAPDH mRNA. 
CCK8 (Dojindo, Japan) solution was added into each well were incubated for $1 \mathrm{~h}$ in the incubator. The absorbance was measured at $450 \mathrm{~nm}$ using a microplate reader.

\begin{abstract}
Apoptosis assay
After miR-21 inhibitor transfection for $72 \mathrm{~h}$, the apoptotic cells were quantified using the Annexin V/PI apoptosis kit (Multiscience, Hangzhou, China). Rat SCs were collected, washed with PBS, and resuspended in $200 \mu \mathrm{L}$ binding buffer containing 5 $\mu \mathrm{L}$ annexin $\mathrm{V}(10 \mu \mathrm{g} / \mathrm{mL})$ for $10 \mathrm{~min}$ in the dark. The cells were then incubated with $10 \mu \mathrm{L}$ PI $(20 \mu \mathrm{g} / \mathrm{mL})$, and the samples were immediately analyzed using flow cytometry (Beckman Coulter, Epics XL, USA). Data acquisition and analysis were performed using CellQuest software.
\end{abstract}

\section{Cell cycle assay}

After miR-21 inhibitor transfection in hypoxic enbviroment for 72 hours, SCs were collected, washed with PBS, and resuspended in $250 \mu \mathrm{L}$ binding buffer. Then the cold dehydrated alcohol was added into this buffer at $4^{\circ} \mathrm{C}$ overnight. After treatment, the cells were collected again and then incubated with $200 \mu \mathrm{L}$ PI $(20 \mu \mathrm{g} / \mathrm{mL})$ using Cell cycle staining kit (Multiscience, Hangzhou, China). The samples were immediately analyzed using flow cytometry (Beckman Coulter, Epics XL, USA). Data acquisition and analysis were performed using CellQuest software.

\section{Data analysis}

For real-time PCR data analysis, we chose the relative quantification method to determine the changes in the expression of the target mRNAs/miRNAs. The change in amplification was normalized to the expression of the GAPDH/U6 RNA. The fold change in expression was calculated for each sample using 2- $\Delta \Delta \mathrm{Ct}$, where $\Delta \Delta \mathrm{CT}=(\mathrm{Ct}$ target gene - Ct GAPDH/U6) PIH-(Ct target gene Ct GAPDH/U6) control. A2- $\Delta \Delta \mathrm{Ct}>1.5$ or $<0.67$ was considered differentially expressed mRNA/miRNA. Differential expression of mRNA/miRNA measured by the real-time PCR array was tested using the Welch t-test. $p$ value $<0.05$ was considered significant.

For other data analysis, Statistical analysis was performed by use of SPSS 17.0. One-way ANOVA was used to compare $\log 10$-transformed relative quantities of target between all groups. Differences in variance between genes were assessed by use of
Bartlett's test. $\mathrm{P}<0.05$ were considered statistically significant for all tests.

\section{RESULTS AND DISCUSSION}

\section{Effect of heregulin-1 $\beta$ on nerve regeneration in} rats with peripheral nerve injury

According to our previous research, we transplanted ANA+SKP-SC+ heregulin- $1 \beta$ into rats which underwent exposure of the right sciatic nerve and detected miR-21 and SOX2 levels by realtime-PCR and western blot assay. As Fig 1 showed, compared to ANA+SKP-SC group, miR-21 level of ANA+SKP-SC+ heregulin-1 $\beta$ group was effectively inhibited (Fig 1A) and SOX2 expression was increased accordingly (Fig 1B). Peripheral nerve injury breaks the neurites, endoneurium, perineurium and the surface of microvessels (Mika et al., 2015).
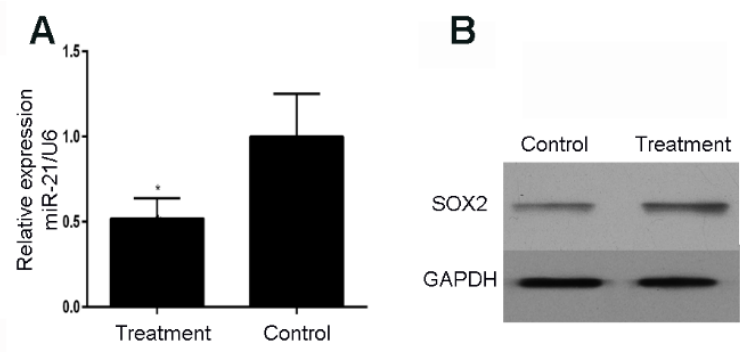

Figure 1 - Expression of miR-21 and SOX2 in rats with exposure of the right sciatic nerve injury as detected by real-time PCR and western blotting. (A) detection of miR21 level after ANA+SKP-SC+ heregulin-1 $\beta$ treatment; (B) detection of SOX2 protein level after ANA+SKP-SC+ heregulin- $1 \beta$ treatment. Data are shown as the mean \pm standard deviation. All detections were repeated independently three times. *indicates $\mathrm{P}<0.05$ versus ANA+SKP-SC group.

Our previous research demonstrated that transplantation of SKP-SCs and ANA in peripheral nerve injury may promote nerve recovery and regeneration. Here, our previous study proposed and revealed that under permissive conditions, transplantation of SKP-SCs and ANA seeded with heregulin-1 $\beta$ may have better effect on nerve regeneration. So we designed our experiment to explore the molecular mechanism of effect of heregulin-1 $\beta$ on peripheral nerve injury. In order to fine the relationship between heregulin- $1 \beta$ and miR21, we firstly transplanted SKPSC+ANA+heregulin-1 $\beta$ into rats with right sciatic nerve injury as our previous study described and then tested the expression of miR-21 and SOX2. We found that miR-21 was also decreased effectively as 
what miR-21 inhibitor did with induced SOX2 expression accordingly, which demonstrated that heregulin-1 $\beta$ may increase the synergistic effect between SKP-SCs and ANA through inhibiting miR21 in vivo.

\section{Detection of miR-21 and SOX2 expression in} hypoxic Schwann cells

The result in Fig 1A and 1B suggested that miR-21 expression was increased time-dependently after SCs were treated with hypoxic environment for $12 \mathrm{~h}, 24 \mathrm{~h}$ and $36 \mathrm{~h}$ (Fig 2A) and the protein level of SOX2 was effectively silenced accordingly (Fig 2B). After miR21 inhibitor transfection for $24 \mathrm{~h}$, miR-21 expression was significantly inhibited (Fig 2C) and SOX2 protein expression was up-regulated as shown in Fig 2D. We isolated and generated the rat hypoxic SCs model to imitate the nerve injury micro-environment according to verified protocol. Results showed the increased miR-21 expression with suppressed SOX2 expression accordingly, which implied that miR-21 expressed highly in SCs with injury.
A

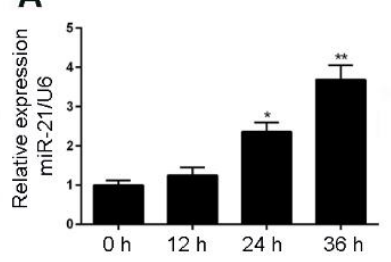

C

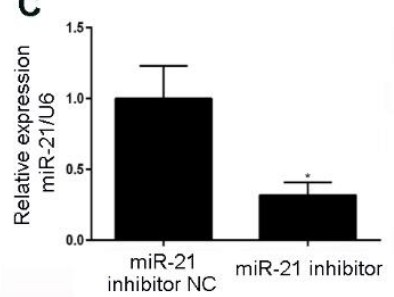

B

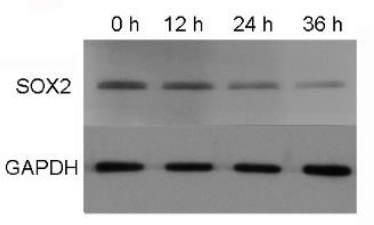

D

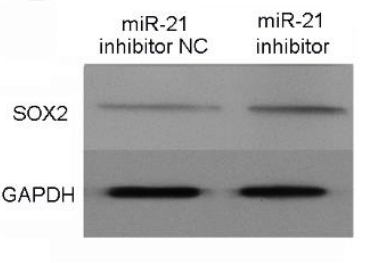

Figure 2 - Expression of miR-21 and SOX2 in hypoxic SCs treated with miR-21 inhibitor as detected by realtime PCR and western blotting. (A) detection of miR-21 level after SCs being treated with hypoxic environment for 12 h, $24 \mathrm{~h}$ and $36 \mathrm{~h}$; (B) detection of SOX2 protein expression after SCs being treated with hypoxic environment for 12 h, $24 \mathrm{~h}$ and $36 \mathrm{~h}$; (C) detection of miR-21 level after SCs being treated with hypoxic environment for $24 \mathrm{~h}$ followed by miR-21 inhibitor transfection for $72 \mathrm{~h}$; (D) detection of miR-21 level after SCs being treated with hypoxic environment for $24 \mathrm{~h}$ followed by miR-21 inhibitor transfection for $72 \mathrm{~h}$. Data are shown as the mean \pm standard deviation. All detections were repeated independently three times. *indicates $\mathrm{P}<0.05$; **indicates $\mathrm{P}<0.01$; versus negative control group.
Effect of miR-21 inhibitor on cell function in hypoxic Schwann cells

Furthermore, we examined the effects of miR-21 inhibitor on cell proliferation of hypoxic SCs. As the result shown in Fig 3, cellular population was induced time-independently at IC50 levels in miR-21 inhibitor group especially at $48 \mathrm{~h}, 72 \mathrm{~h}$ and $96 \mathrm{~h}$ compared to NC group.

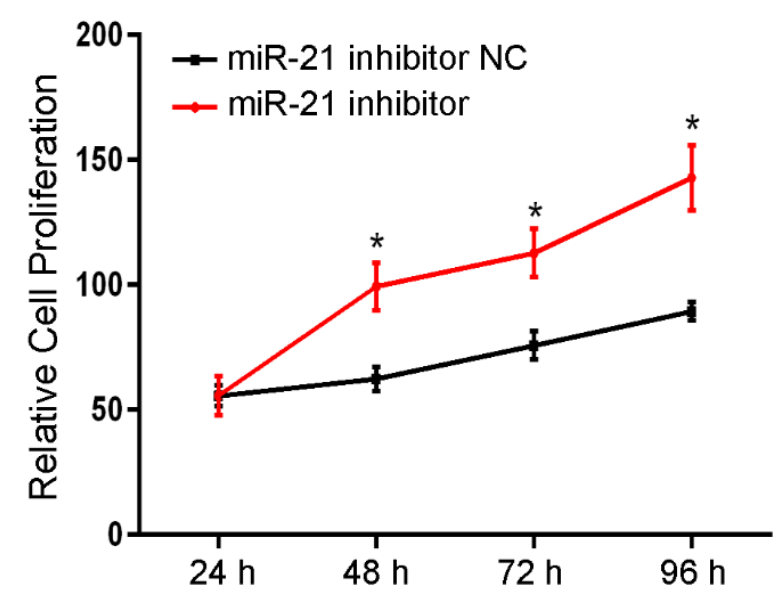

Figure 3 - Down regulation of miR-21 induces growth of $\mathrm{SCs}$ in vitro. Cell numbers were counted in following time points: 24 hours, 48 hours, 72 hours and 96 hours. Cell viability was measured using CCK8 assay. Data are shown as the mean \pm standard deviation. All testings were repeated independently three times. *Indicates $\mathrm{P}<0.05$ versus the data of negative group detected at the same time point.

Cell apoptosis was analyzed using flow cytometry after miR-21 inhibitor transfection for $72 \mathrm{~h}$ based on CCK 8 results. Compared to NC group, SCs exposure to miR-21 inhibitor presented typical inhibition from apoptotic morphology with cell shrinkage, nuclear fragmentation, and cellular rupture into debris. The occurrence of apoptosis was significantly lower in cells treated with miR-21 inhibitor with respect to negative control group (Fig 4A and 4B).
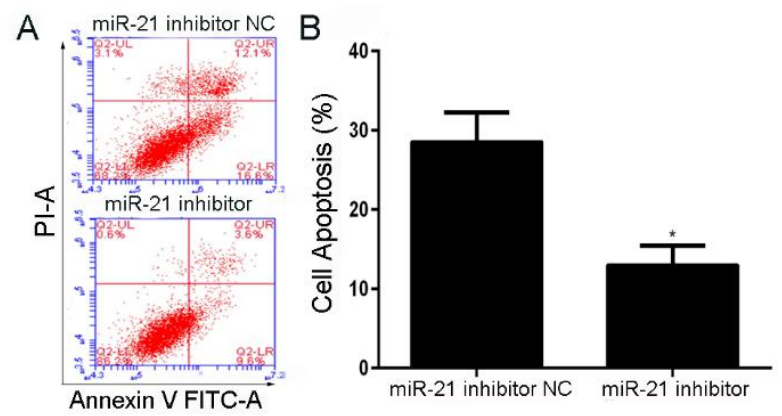

Figure 4 - Inhibition of apoptosis change. (A) SCs were transfected with miR-21 inhibitor for 72 hours before 
being harvested for apoptosis test; (B) The percentage of SCs apoptosis in time point of $72 \mathrm{~h}$. Data are shown as the mean \pm standard deviation. All experiments were repeated independently three times. *Indicates $\mathrm{P}<0.05$ versus the data from negative control group detected at the same time point.

To investigate whether the cell cycle arrest is one of the major cellular responses to treatments, we performed the cell cycle analysis by flow cytometry. Cell cycle distribution was analyzed using flow cytometry after miR-21 inhibitor transfection and hypoxia pre-treatment for 72 hours. Compared to NC group, cells accumulated in G2 phase were decreased in response to miR-21 inhibitor, and this response was further augmented. The ratio of G2/G1 was decreased and $\mathrm{G} 1$ cell cycle arrest was induced after miR-21 inhibitor transfection (Fig 5A and 5B).
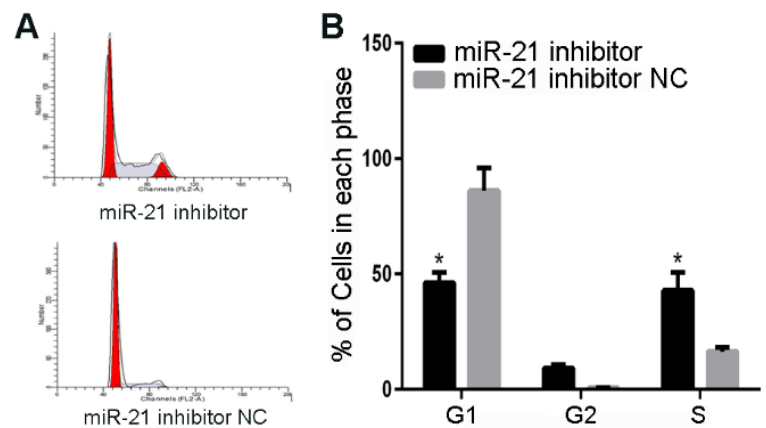

Figure 5 - Treatment effect on cell cycle. (A) SCs were transfected with miR-21 inhibitor for 72 hours before being harvested for cell cycle test; (B) Cell number distribution in different phases ( $S$ phase, G1 phase and G2 phase) examined by flow cytometry was calculated withexposure in hypoxic environment for $24 \mathrm{~h}$ followed by miR-21 inhibitor transfection for $72 \mathrm{~h}$. Data are shown as the mean \pm standard deviation. All experiments were repeated independently three times. * Indicates $\mathrm{P}<0.05$ versus the data from negative control group detected at the same cell phase.

As described, during development of the peripheral nerve injury, it is important that Schwann cells differentiate into highly specialized myelinating and nonmyelinating cells and maintain the ability to revert back to a non differentiated, proliferative phenotype (Mizisin, 2014; Wang et al., 2015). In this recovery process, $\mathrm{SOX} 2$, one of the group of transcription factors, may be decreased in immature Schwann cells as the Schwann cell begin to differentiate with the form of myelin, and then induce pluripotent stem cells from adult somatic cells (Kegler et al., 2015; Le et al., 2005).
In adult peripheral nerves, SOX2 expression is reinduced in the Schwann cell following nerve injury(Wang et al., 2010). Recent study indicates that SOX2 may encode a transcription factor that is crucial for maintenance of neural stem cell pluripotency (Hauser et al., 2012). Enforced expression of SOX2 inhibits SCs differentiation, promots increased responsiveness to proliferative stimuli, suppresses myelin gene expression and prevents the ability to myelinate axons, which may result from inhibiting Egr2 expression, and thereby, suppresses subsequent expression of myelin genes (Le et al., 2005).

It has been found that miR-21 down-regulate SOX2 protein expression by binding to the 3'UTR region of SOX2 mRNA (Trohatou et al., 2014). Silencing SOX2 expression in neural crest stem cells may reverse the inhibition of differentiation from neural crest stem cells to Schwann cells conducted by antagomir-21, which suggests that highly expressed miR-21 may promote this differentiation through inhibiting SOX2 protein expression (Ni et al., 2014). Other research shows that miR-21 might have specifically function by inhibiting the primarily level of SOX2 in human mesenchymal stem cells (MSCs) and might also act as a key molecule determining MSCs proliferation and differentiation (Trohatou et al., 2014; Yang and Rana, 2013).Also for other diseases such as glioma, miR-21 and SOX2 are revealed tightly regulated already during embryogenesis and define a distinct population with putative tumor cell of origin characteristics (Polajeva et al., 2012).

\section{CONCLUSIONS}

In conclusion, it was aligned with our results that heregulin-1 $\beta$ we chose may increase the synergistic effect between SKP-SC and ANA which may promote the recovery and regeneration of peripheral nerve injury through inhibiting miR-21 and inducing SOX2 consequently.

\section{REFERENCE}

Chhabra, A, Ahlawat, S, Belzberg, A, and Andreseik, G (2014): Peripheral nerve injury grading simplified on MR neurography: As referenced to Seddon and Sunderland classifications. Indian J Radiol Imaging 24, 217-24. 
Evans, GR (2001): Peripheral nerve injury: a review and approach to tissue engineered constructs. Anat Rec 263, 396-404.

Fernandes, KJ, McKenzie, IA, Mill, P, Smith, KM, Akhavan, M, Barnabe-Heider, F, Biernaskie, J, Junek, A, Kobayashi, NR, Toma, JG, Kaplan, DR, Labosky, PA, Rafuse, V, Hui, CC, and Miller, FD (2004): A dermal niche for multipotent adult skin-derived precursor cells. Nat Cell Biol 6, 1082-93.

Gomez-Sanchez, JA, Carty, L, Iruarrizaga-Lejarreta, M, Palomo-Irigoyen, M, Varela-Rey, M, Griffith, M, Hantke, J, Macias-Camara, N, Azkargorta, M, Aurrekoetxea, I, De Juan, VG, Jefferies, HB, Aspichueta, P, Elortza, F, Aransay, AM, MartinezChantar, ML, Baas, F, Mato, JM, Mirsky, R, Woodhoo, A, and Jessen, KR (2015): Schwann cell autophagy, myelinophagy, initiates myelin clearance from injured nerves. J Cell Biol 210, 153-68.

Griffin, LB, Sakaguchi, R, McGuigan, D, Gonzalez, MA, Searby, C, Zuchner, S, Hou, YM, and Antonellis, A (2014): Impaired function is a common feature of neuropathy-associated glycyl-tRNA synthetase mutations. Hum Mutat 35, 1363-71.

Hauser, S, Widera, D, Qunneis, F, Muller, J, Zander, C, Greiner, J, Strauss, C, Luningschror, P, Heimann, P, Schwarze, H, Ebmeyer, J, Sudhoff, H, Arauzo-Bravo, MJ, Greber, B, Zaehres, H, Scholer, H, Kaltschmidt, C, and Kaltschmidt, B (2012): Isolation of novel multipotent neural crest-derived stem cells from adult human inferior turbinate. Stem Cells Dev 21, 742-56.

Jessen, KR, and Mirsky, R (1992): Schwann cells: early lineage, regulation of proliferation and control of myelin formation. Curr Opin Neurobiol 2, 575-81.

Kaya, Y, and Sarikcioglu, L (2015): Sir Herbert Seddon (1903-1977) and his classification scheme for peripheral nerve injury. Childs Nerv Syst 31, 177-80.

Kegler, K, Spitzbarth, I, Imbschweiler, I, Wewetzer, K, Baumgartner, W, and Seehusen, F (2015): Contribution of Schwann Cells to Remyelination in a Naturally Occurring Canine Model of CNS Neuroinflammation. PLOS ONE 10, e0133916.

Kitada, M (2012): Mesenchymal cell populations: development of the induction systems for Schwann cells and neuronal cells and finding the unique stem cell population. Anat Sci Int 87, 24-44.

Le, N, Nagarajan, R, Wang, JY, Araki, T, Schmidt, RE, and Milbrandt, J (2005): Analysis of congenital hypomyelinating Egr2Lo/Lo nerves identifies Sox2 as an inhibitor of Schwann cell differentiation and myelination. Proc Natl Acad Sci U S A 102, 2596-601.

Li, WW, Le Goascogne, C, Schumacher, M, Pierre, M, and Courtin, F (2001): Type 2 deiodinase in the peripheral nervous system: induction in the sciatic nerve after injury. Neuroscience 107, 507-18.

Liu, MW, Liu, R, Wu, HY, Li, YY, Su, MX, Dong, MN, Zhang, W, and Qian, CY (2016): Radix puerariae extracts ameliorate paraquat-induced pulmonary fibrosis by attenuating follistatin-like 1 and nuclear factor erythroid 2p45-related factor-2 signalling pathways through downregulation of miRNA-21 expression. $B M C$ Complement Altern Med 16, 11.

McKenzie, IA, Biernaskie, J, Toma, JG, Midha, R, and Miller, FD (2006): Skin-derived precursors generate myelinating Schwann cells for the injured and dysmyelinated nervous system. J Neurosci 26, 6651-60.

Mika, JK, Schwarz, K, Wanzenboeck, HD, Scholze, P, and Bertagnolli, E (2015): Investigation of neurotrophic factor concentrations with a novel in vitro concept for peripheral nerve regeneration. J Neurosci Res 93, 163140.

Mizisin, AP (2014): Mechanisms of diabetic neuropathy: Schwann cells. Handb Clin Neurol 126, 401-28.

Ni, Y, Zhang, K, Liu, X, Yang, T, Wang, B, Fu, L, A, L, and Zhou, Y (2014): miR-21 promotes the differentiation of hair follicle-derived neural crest stem cells into Schwann cells. Neural Regen Res 9, 828-36.

Pfister, BJ, Gordon, T, Loverde, JR, Kochar, AS, Mackinnon, SE, and Cullen, DK (2011): Biomedical engineering strategies for peripheral nerve repair: surgical applications, state of the art, and future challenges. Crit Rev Biomed Eng 39, 81-124.

Polajeva, J, Swartling, FJ, Jiang, Y, Singh, U, Pietras, K, Uhrbom, L, Westermark, B, and Roswall, P (2012): miRNA-21 is developmentally regulated in mouse brain and is co-expressed with SOX2 in glioma. BMC Cancer 12, 378 .

Saheb-Al-Zamani, M, Yan, Y, Farber, SJ, Hunter, DA, Newton, P, Wood, MD, Stewart, SA, Johnson, PJ, and Mackinnon, SE (2013): Limited regeneration in long acellular nerve allografts is associated with increased Schwann cell senescence. Exp Neurol 247, 165-77.

Sakai, A, and Suzuki, H (2013): Nerve injury-induced upregulation of miR-21 in the primary sensory neurons contributes to neuropathic pain in rats. Biochem Biophys Res Commun 435, 176-81.

Seo, SY, Min, SK, Bae, HK, Roh, D, Kang, HK, Roh, S, Lee, S, Chun, GS, Chung, DJ, and Min, BM (2013): A laminin-2-derived peptide promotes early-stage peripheral nerve regeneration in a dual-component artificial nerve graft. J Tissue Eng Regen Med 7, 788800.

Singh, SK, Marisetty, A, Sathyan, P, Kagalwala, M, Zhao, Z, and Majumder, S (2015): REST-miR-21-SOX2 axis maintains pluripotency in E14Tg2a.4 embryonic stem cells. Stem Cell Res 15, 305-11.

Sparling, JS, Bretzner, F, Biernaskie, J, Assinck, P, Jiang, Y, Arisato, H, Plunet, WT, Borisoff, J, Liu, J, Miller, FD, and Tetzlaff, W (2015): Schwann cells generated from neonatal skin-derived precursors or neonatal peripheral nerve improve functional recovery after acute transplantation into the partially injured cervical spinal cord of the rat. $J$ Neurosci 35, 6714-30.

Trohatou, O, Zagoura, D, Bitsika, V, Pappa, KI, Antsaklis, A, Anagnou, NP, and Roubelakis, MG (2014): Sox2 suppression by miR-21 governs human mesenchymal stem cell properties. Stem Cells Transl Med 3, 54-68. 
Vroemen, M, Caioni, M, Bogdahn, U, and Weidner, N (2007): Failure of Schwann cells as supporting cells for adult neural progenitor cell grafts in the acutely injured spinal cord. Cell Tissue Res 327, 1-13.

Walsh, SK, Gordon, T, Addas, BM, Kemp, SW, and Midha, R (2010): Skin-derived precursor cells enhance peripheral nerve regeneration following chronic denervation. Exp Neurol 223, 221-8.

Wang, J, Zhang, P, Wang, Y, Kou, Y, Zhang, H, and Jiang, B (2010): The observation of phenotypic changes of Schwann cells after rat sciatic nerve injury. Artif Cells Blood Substit Immobil Biotechnol 38, 24-8.

Wang, L, Sanford, MT, Xin, Z, Lin, G, and Lue, TF (2015): Role of Schwann cells in the regeneration of penile and peripheral nerves. Asian J Androl 17, 776-82.
Yang, CS, and Rana, TM (2013): Learning the molecular mechanisms of the reprogramming factors: let's start from microRNAs. Mol Biosyst 9, 10-7.

Zhang, P, Lu, X, Chen, J, and Chen, Z (2014): Schwann cells originating from skin-derived precursors promote peripheral nerve regeneration in rats. Neural Regen Res 9, 1696-702.

Zhang, YR, Ka, K, Zhang, GC, Zhang, H, Shang, Y, Zhao, GQ, and Huang, WH (2015): Repair of peripheral nerve defects with chemically extracted acellular nerve allografts loaded with neurotrophic factors-transfected bone marrow mesenchymal stem cells. Neural Regen Res 10, 1498-506. 